\title{
Thymoma in Patient with Myasthenia Gravis Has Significantly Fewer Forkhead Box P3 Positive Lymphocytes than that without One
}

\author{
TATSUYA NISHI, SHINTARO YOKOYAMA, SHINZO TAKAMORI, TOSHIHIRO MATSUO, \\ DAIGO MURAKAMI, YOSHITO AKAGI AND KOICHI OHSHIMA* \\ Department of Surgery and Pathology*, Kurume University School of Medicine, \\ Kurume 830-0011, Japan
}

Received 16 December 2014, accepted 2 March 2015

J-STAGE advance publication 30 June 2015

Edited by KOJI NAGAFUJI

\begin{abstract}
Summary: Forkhead box P3 (FoxP3) is known as a pivotal and specific transcriptional factor of regulatory T cells, and are implicated in various immune diseases including myasthenia gravis (MG). The aim of this study was to investigate the relationships between FoxP3 expression of lymphocytes in thymoma and clinicopathological characteristics, particularly MG status in thymoma patients.

We reviewed 83 thymoma specimens, including 22 from MG patients, and evaluated the FoxP3 expression of lymphocytes in thymoma using immunohistochemistry (IHC). Statistical association was evaluated using chisquare test and Fisher's exact test.

Thirty-four cases $(41.0 \%)$ were classified as FoxP3 positive. There were no statistical differences in sex $(P=0.289)$, age $(P=0.536)$, Masaoka stage $(P=0.086)$, WHO histological classification $(P=0.097)$, or Myasthenia Gravis Foundation of America (MGFA) Clinical Classification $(P=0.117)$ between FoxP3 positive and negative cases. In contrast, thymoma in cases with MG showed significantly fewer FoxP3 positive lymphocytes than those in cases without MG $(P=0.037)$. Moreover, cases with anti-acetylcholine receptor antibody titer equal to or greater than the normal limit also showed significantly fewer FoxP3 positive lymphocytes than cases within the normal limit $(P<0.001)$.

Our result indicated the possibility that the decrease of FoxP3 positive lymphocytes in thymoma may lead to the development of MG and to an increase in anti-acetylcholine receptor antibodies. In addition, FoxP3 positive lymphocytes might be a useful biomarker for evaluation of the risk of MG onset, and could open the way to more effective therapeutic strategies in thymoma patients.
\end{abstract}

Key words regulatory $\mathrm{T}$ cell, FoxP3, thymoma, myasthenia gravis

\section{INTRODUCTION}

Thymomas are derived from thymic epithelia and they have a variety of histological features. In 1999, the World Health Organization (WHO) published the histological classification system for thymic tumors [1], and a detailed reclassification was done in 2004 [2].
Thymomas are classified mainly into five subtypes, $\mathrm{A}, \mathrm{AB}, \mathrm{B} 1, \mathrm{~B} 2$, and B3. Type A thymomas are thought to derive from the medulla, type $B$ from the cortex, and type $\mathrm{AB}$ are a mixed type. Type $\mathrm{B}$ thymomas are further subdivided into B1, B2, and B3 depending on the percentage of lymphocytes and extent of epithelial cell atypia $[3,4]$.

Corresponding author: Koichi Ohshima M.D. Department of Pathology, Kurume University School of Medicine, 67 Asahi-machi, Kurume 830-0011, Japan. Tel: +81-942-31-7547 Fax: +81-942-31-0342 E-mail: ohshima_kouichi@med.kurume-u.ac.jp

Abbreviations: Ach-R, acetylcholine receptor; FFPE, formalin-fixed paraffin-embedded; FoxP3, forkhead box P3; IHC, immunohistochemistry; MG, myasthenia gravis; MGFA, Myasthenia Gravis Foundation of America; Tregs, regulatory T cells; Tris-EDTA, Tris-ethylent diamine tetra acetic acid; WHO, World Health Organization. 
The most common paraneoplastic phenomenon associated with thymoma is myasthenia gravis (MG), which affects $25-45 \%$ of thymoma patients [4-6]. Type B thymomas in particular are frequently associated with MG [7]. Myasthenia gravis is an autoimmune disease caused by $\mathrm{CD}^{+}{ }^{+} \mathrm{T}$-cell-dependent development of anti-acetylcholine receptor (Ach-R) antibodies that cause muscle weakness by impairing neuromuscular transmission [8-10]. Ströbel et al. [11] reported that intra-tumorous naive $\mathrm{CD} 4^{+} \mathrm{T}$ cells were present in thymomas associated with $\mathrm{MG}$, and concluded that paraneoplastic MG is closely associated with the capacity of thymomas to produce and export naive $\mathrm{CD}^{+}$ $\mathrm{T}$ cells.

Regulatory T cells (Tregs), which are one of the subtypes of $\mathrm{CD}^{+} \mathrm{T}$ cells, have been shown to play a critical role in the prevention of organ-specific autoimmunity and allograft rejection. Tregs exert an autologous inhibitory effect on the activation of antigen-specific $T$ cell subsets and can control self-reactive $T$ cell responses [12-14]. Recent studies have shown that the maturation of $\mathrm{CD} 4{ }^{+} \mathrm{CD} 25^{+}$Tregs was impaired in MG-associated thymoma [15]. In addition, forkhead box P3 (FoxP3) is considered to be a specific transcriptional factor required for the differentiation and development of Tregs, and is widely used as a specific marker of this subset [16,17].

We investigated FoxP3 positive lymphocytes in thymoma tissue samples using immunohistochemistry (IHC), and surveyed correlations between its expression and clinicopathological characteristics including MG, anti-Ach-R antibody titer, and the severity of MG symptoms.

\section{MATERIALS AND METHODS}

\section{Patients}

We reviewed formalin-fixed paraffin-embedded (FFPE) tissue samples from 83 cases of thymoma which underwent thymectomy at Kurume University Hospital between 1990 and 2007. Pathological diagnoses were performed by two pathologists (NT and OK) in all cases, based on the 2004 WHO histological classification. Clinical data were reviewed by reference to the patient's clinical charts.

\section{IHC and definition of Foxp 3 expression}

A block containing the broadest available surface of tumor tissue was cut into $4 \mu \mathrm{m}$ sections. The detailed protocol of IHC of FoxP3 was as follows: Deparaffinized sections were pretreated with the aim of antigen retrieval in a microwave oven at $95^{\circ} \mathrm{C}$ for
$40 \mathrm{~min}$ in tris-ethylenediaminetetraacetic acid buffer (Tris-EDTA buffer). $3 \% \mathrm{H}_{2} \mathrm{O}_{2}$ solution was used to blockade the endogenous peroxidase activity. Samples were incubated for two hours in the primary antiFoxP3 antibody (1:40, mouse monoclonal, PCH101, eBioscience, San Diego, USA) at room temperature. The secondary antibody of Envision System polymer (Dako, Tokyo, Japan) was used for $30 \mathrm{~min}$ at room temperature. Staining was visualized by incubation with diaminobenzine (Dako) [18]. In this technique, we used tissue samples of pericardium as a negative control and confirmed the experimental validity.

Two investigators (NT and $\mathrm{OK}$ ) evaluated the FoxP3 expression without knowing the clinical details of each case. The number of FoxP3 positive lymphocytes was counted by an optical microscope at a magnification of $\times 400$, and the number of positive cells was averaged over five individual viewing fields. Cases with more than 10 FoxP3 positive lymphocytes per field were defined as positive cases, and cases with 10 or less cells per field were defined as negative cases.

\section{Statistical analysis}

JMP software (SAS Institute, Cary, NC, USA) was used for all statistical analyses in this study. The chisquare test was performed for comparison of clinicopathological classifications and FoxP3 expression, although Fisher's exact test was adapted when necessary. A $P$ value $<0.05$ was considered to indicate a significant difference.

\section{RESULTS}

\section{Clinicopathological characteristics}

Patient's characteristics of the 83 thymoma cases are shown in Table 1. There were 35 males and $48 \mathrm{fe}$ males with a median age of 56 years. Thymomas were histologically classified into type $\mathrm{A}$ in three cases (3.6\%), type $\mathrm{AB}$ in 25 cases (30.1\%), type $\mathrm{B} 1$ in 21 cases (25.3\%), type B2 in 25 cases (30.1\%), and type B3 in nine cases (10.8\%) in accordance with the 2004 WHO histological classification. Twenty-two cases (26.5\%) were complicated with MG, with no case $(0 \%)$ in type $\mathrm{A}$, four cases $(16.0 \%)$ in type $\mathrm{AB}$, eight cases $(38.1 \%)$ in type B1, seven cases (28.0\%) in type B2, and three cases (33.3\%) in type B3. Furthermore, the elevation of anti-Ach-R antibody titer was observed in 28 cases (33.7\%), with no case (0\%) in type A, five cases (50.0\%) in type AB, seven cases (53.9\%) in type B1, 12 cases $(75.0 \%)$ in type B2, and four cases (57.1\%) in type B3. All MG cases showed the eleva- 
TABLE 1.

Patient Characteristics

\begin{tabular}{|c|c|c|}
\hline Variables & $\begin{array}{l}\text { Number of patients } \\
\qquad(\mathrm{n}=83)\end{array}$ & $\%$ \\
\hline \multicolumn{3}{|l|}{ Sex } \\
\hline Male & 35 & $42.2 \%$ \\
\hline Female & 48 & $57.8 \%$ \\
\hline \multicolumn{3}{|l|}{ Age (years) } \\
\hline Median [range] & $56[27-78]$ & \\
\hline$<56$ & 40 & $48.2 \%$ \\
\hline$\geq 56$ & 43 & $51.8 \%$ \\
\hline \multicolumn{3}{|l|}{ Masaoka stage } \\
\hline I & 41 & $49.4 \%$ \\
\hline II & 27 & $32.5 \%$ \\
\hline III & 10 & $12.0 \%$ \\
\hline IVa & 0 & $0.0 \%$ \\
\hline $\mathrm{IVb}$ & 5 & $6.0 \%$ \\
\hline \multicolumn{3}{|c|}{ WHO classification } \\
\hline Type A & 3 & $3.6 \%$ \\
\hline Type AB & 25 & $30.1 \%$ \\
\hline Type B1 & 21 & $25.3 \%$ \\
\hline Type B2 & 25 & $30.1 \%$ \\
\hline Type B3 & 9 & $10.8 \%$ \\
\hline \multicolumn{3}{|l|}{ MG } \\
\hline Present & 22 & $26.5 \%$ \\
\hline Absent & 61 & $73.5 \%$ \\
\hline \multicolumn{3}{|c|}{ Anti-Ach-R antibody titer (nmol/L) } \\
\hline$<0.2$ & 20 & $24.1 \%$ \\
\hline$\geq 0.2$ & 28 & $33.7 \%$ \\
\hline Unknown & 35 & $42.2 \%$ \\
\hline \multicolumn{3}{|c|}{ MGFA Clinical Classification (MG cases, $n=22$ ) } \\
\hline I & 3 & $13.6 \%$ \\
\hline IIa & 14 & $63.6 \%$ \\
\hline IIb & 4 & $18.2 \%$ \\
\hline IIIIa & 0 & $0.0 \%$ \\
\hline IIIb & 0 & $0.0 \%$ \\
\hline IVa & 0 & $0.0 \%$ \\
\hline $\mathrm{IVb}$ & 0 & $0.0 \%$ \\
\hline $\mathrm{V}$ & 1 & $4.5 \%$ \\
\hline
\end{tabular}

Abbreviations: WHO, World Health Organization; MG, myasthenia gravis;

Anti-Ach-R, anti-acetylcholine receptor; MGFA, Myasthenia Gravis Foundation of America.

tion of anti-Ach-R antibody titer, as did six cases (9.8\%) without MG. MG cases were categorized as class I in three cases $(13.6 \%)$, class IIa in 14 cases (63.6\%), IIb in four cases $(18.2 \%)$, and $\mathrm{V}$ in one case (4.5\%), according to the Myasthenia Gravis Foundation of America (MGFA) Clinical Classification, which is an internationally accepted severity scoring system of MG.

Immunohistochemical FoxP3 expression oflymphocytes in thymoma

In this study, the FoxP3 was expressed in 34 cases 


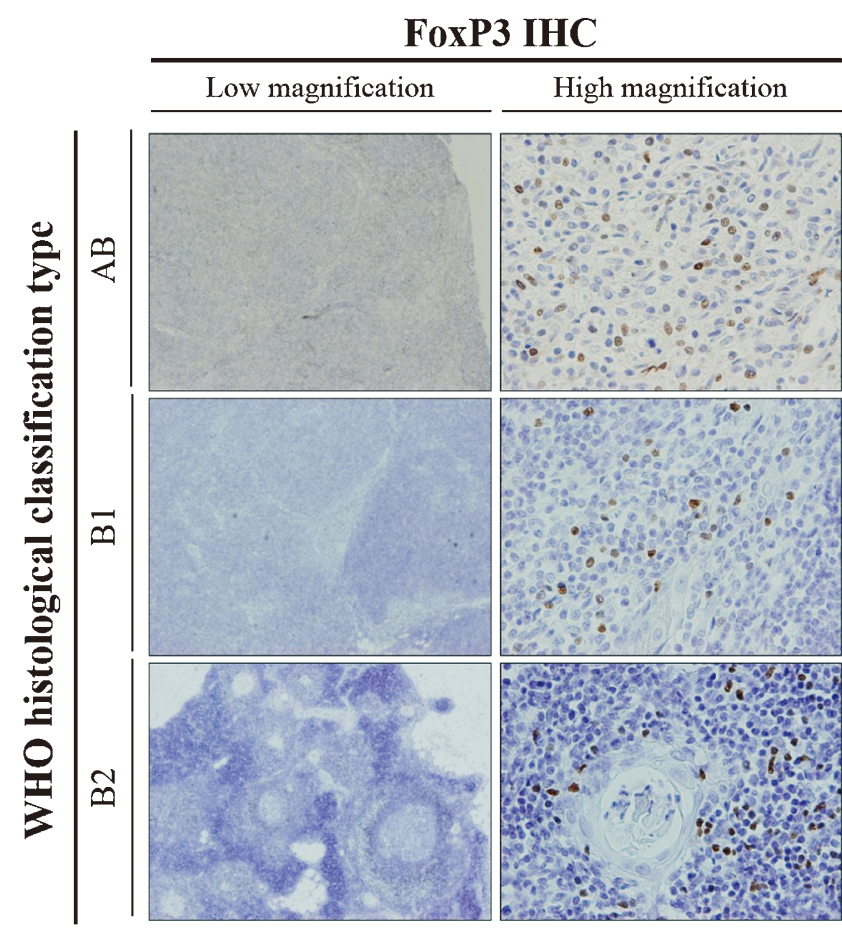

Fig. 1. Representative microphotographs of immunohistochemistry in FoxP3 positive expression cases. Type AB case (upper row), type B1 case (middle row), and type B2 case (lower row) are presented. Immunohistochemistry of FoxP3 revealed positive expression in over 10 lymphocytes per field at magnification $\times 400$. (left column: magnification $\times 40$, right column: magnification $\times 400$ )

(41.0\%), all of which showed infiltrating lymphocytes with diffusely stained nuclei but no cytoplasmic staining (Fig. 1). FoxP3 expression was not observed in any of the epithelial tumor cells. Furthermore, FoxP3 expression of lymphocytes revealed almost uniform staining proportion in the whole specimen. Only five cases with MG (22.7\%) were found to be FoxP3 positive, in contrast with 29 cases $(47.5 \%)$ in cases without MG. Additionally, in terms of anti-Ach-R antibody titer, 13 cases $(65.0 \%)$ were determined as FoxP3 positive at less than the normal limit $(<0.2 \mathrm{nmol} / \mathrm{L})$, while only five cases $(17.8 \%)$ were determined as positive at equal to or more than the normal limit ( $\geq 0.2 \mathrm{nmol} / \mathrm{L})$.

Statistical association between FoxP3 expression of lymphocytes and clinicopathological features in thymoma

The statistical association between FoxP3 expression of lymphocytes in thymoma and clinicopathological features is shown in Table 2. Cases with MG showed significantly fewer FoxP3 positive lymphocytes than those without MG in thymoma $(P=0.037)$.
Moreover, cases with anti-Ach-R antibody titer equal to or greater than the normal limit also showed significantly fewer FoxP3 positive lymphocytes compared with cases having less than the normal limit $(P<0.001)$. In contrast, there were no significant differences in sex $(P=0.289)$, age $(P=0.536)$, Masaoka stage $(P=0.086)$, WHO histological classification $(P=0.097)$, and MGFA Clinical Classification $(P=0.117)$.

\section{DISCUSSION}

We found that $41.0 \%$ of the thymoma tissue samples evaluated in the present study contained FoxP3 positive lymphocytes in IHC. We detected significantly fewer FoxP3 positive lymphocytes in thymoma of MG patients than in those without MG. In addition, we also demonstrated that there are significantly fewer FoxP3 positive lymphocytes in thymoma patients with elevated anti-Ach-R antibody titer than in those without anti-Ach-R antibody elevation.

Sakaguchi et al. [19] were the first to propose Tregs as $\mathrm{CD} 4^{+} \mathrm{CD} 25^{+}$cells in 1995 , which emphasize the suppressive role in immune response in the periphery, following elucidation of its key transcriptional factor FoxP3 [16]. Gene transfer of FoxP3 converts naive $\mathrm{CD} 4^{+} \mathrm{CD} 25^{-} \mathrm{T}$ cells into a regulatory phenotype in both mice and humans and is required for Tregs function $[20,21]$. Accumulated evidence shows that Tregs actively suppress the activation and expansion of self-reactive $\mathrm{T}$ cells by cell-to-cell attachment, thereby preventing autoimmune disease $[22,23]$. It is also reported that the depletion of $\mathrm{CD} 4{ }^{+} \mathrm{CD} 25^{+} \mathrm{T}$ cells from normal animals leads to spontaneous development of various autoimmune diseases such as autoimmune gastritis, thyroiditis, and type 1 diabetes, as well as inflammatory bowel disease [24].

We found that thymomas in MG patients contained significantly fewer FoxP3 positive lymphocytes than those in patients without MG. This result suggests that FoxP3 positive lymphocytes have the ability to contribute to suppression of autoimmune reaction, as can be seen in the other autoimmune diseases described above. Furthermore, Fattorossi et al. [25] suggested that a deficiency of $\mathrm{CD} 4{ }^{+} \mathrm{CD} 25^{+}$Tregs favors the development of $\mathrm{MG}$ and that their normalization is an important clinical benefit of immunosuppressive therapy. Their considerations and our results propose that the evaluation of FoxP3 expression in lymphocytes in thymoma might be a predictive biomarker for risk evaluation of MG onset, and could lead to a new therapeutic strategy in MG patients.

This study also showed that thymomas with ele- 
TABLE 2

Statistical analysis between clinicopathological features and FoxP3 expression

\begin{tabular}{|c|c|c|c|}
\hline Variables & $\begin{array}{l}\text { FoxP3 positive } \\
\quad(\mathrm{n}=34)\end{array}$ & $\begin{array}{l}\text { FoxP3 negative } \\
\quad(\mathrm{n}=49)\end{array}$ & $P$ \\
\hline \multicolumn{4}{|l|}{ Sex } \\
\hline Male & 12 & 23 & 0.289 \\
\hline Female & 22 & 26 & \\
\hline \multicolumn{4}{|l|}{ Age (years) } \\
\hline$<56$ & 15 & 25 & 0.536 \\
\hline$\geq 56$ & 19 & 24 & \\
\hline \multicolumn{4}{|l|}{ Masaoka stage } \\
\hline I / II & 31 & 37 & 0.086 \\
\hline III / IV & 3 & 12 & \\
\hline \multicolumn{4}{|c|}{ WHO histological classification } \\
\hline Type A/AB & 15 & 13 & 0.097 \\
\hline Type B1/B2/B3 & 19 & 36 & \\
\hline \multicolumn{4}{|l|}{ MG } \\
\hline Present & 5 & 17 & $0.037 *$ \\
\hline Absent & 29 & 32 & \\
\hline \multicolumn{4}{|c|}{ Anti-Ach-R antibody titer $(\mathrm{nmol} / \mathrm{L}) * *$} \\
\hline$<0.2$ & 13 & 7 & $<0.001 *$ \\
\hline$\geq 0.2$ & 5 & 23 & \\
\hline \multicolumn{4}{|c|}{ MGFA Clinical Classification (MG cases, $\mathrm{n}=22$ ) } \\
\hline I & 2 & 1 & 0.117 \\
\hline $\mathrm{IIa} / \mathrm{IIb} / \mathrm{V}$ & 3 & 16 & \\
\hline
\end{tabular}

Abbreviations: WHO, World Health Organization; MG, myasthnia gravis; Anti-Ach-R, anti-acetylcholine receptor; MGFA, Myasthenia Gravis Foundation of America.

$* \mathrm{P}<0.05$, ** excluded unknown cases

vated anti-Ach-R antibody titer had significantly fewer FoxP3 positive lymphocytes than those without elevated anti-Ach-R antibody. This fact suggests that the down-regulation of FoxP3 of lymphocytes may lead to the production of anti-Ach-R antibody, which then results in the pathogenesis of MG. Wang et al. [26] also reported that a decreased number of circulating $\mathrm{CD} 4{ }^{+} \mathrm{CD} 25^{+}$Tregs in MG patients was associated with the positive-MG sera of anti-Ach-R antibody titer, although the relationship between FoxP $3^{+}$lymphocytes in the periphery and the anti-Ach-R antibody titer remains uncertain. Their report and our current results indicate that a decrease of some population of Tregs is present in both the microenvironment of thymoma and in the systemic circulation in MG patients. These results also have the potential to lead to better clinical follow-up and therapeutic strategies in MG patients.

On the other hand, FoxP3 expression in lymphocytes in thymoma of MG patients was not associated with MG severity, according to the MGFA Clinical
Classification. However, this result may be due to the small sample size in our study, because class $\mathrm{IIa} / \mathrm{IIb} / \mathrm{V}$ cases obviously showed a tendency to have fewer FoxP3 positive cases $(3 / 19,15.8 \%)$ as compared with class I cases $(2 / 3,66.6 \%)$ (Table 2$)$. Moreover, the frequency of FoxP3 positive lymphocytes in thymoma was associated with anti-Ach-R titer in our study, as we have described. The association between clinical severity and anti-Ach-R antibody titer remains controversial, although some reports suggested the usefulness of repeated anti-Ach-R antibody measurements in evaluation of clinical development of MG [27]. No studies have examined the association of FoxP3 expression of lymphocytes in thymoma with MG and clinical MG severity, therefore further studies including a large number of MG cases may resolve this question, and could lead to clinical initiatives for the treatment of MG.

Our study has some limitations. First, we surveyed only FoxP3 expression as a specific marker of Tregs. 
In general, Tregs have been widely defined as $\mathrm{CD} 4^{+}$ $\mathrm{CD} 25^{+}$lymphocytes in past studies, although recent studies have clarified that FoxP3 is a master regulator of Treg cell function [28]. In addition, it has been reported that the frequency of FoxP3 positive lymphocytes compared with $\mathrm{CD} 4{ }^{+} \mathrm{CD} 25^{+} \mathrm{T}$ cells in peripheral blood was lower in patients with MG than in those without it [29], which suggests that FoxP3 plays a special role in Tregs. Further study of FoxP3 expression in lymphocytes in thymoma from MG patients including CD4 and CD25 might provide helpful information for elucidating the biological interaction of Tregs in the thymoma microenvironment. Second, we investigated FoxP3 expression only with IHC. More investigations including FoxP3 gene analysis would develop the results of our study. Third, our study had a small sample size, especially in MG cases. Future studies should include a larger sample size of MG cases enabling the further elucidation of relationships between FoxP3 expression and MG status, including symptoms, anti-Ach-R receptor antibody titer, and MGFA Clinical Classification.

\section{REFERENCES}

1. Rosai J, and Sobin LH. Histological typing of tumours of the thymus. World Health Organization international histological classification of tumors. Second Edition. New York: 1999; Springer 1999; 2:65.

2. Travis WD, Brambilla E, Muller-Hermelink HK, and Harrys CC. World Health Organization classification of tumours. Pathology and genetics of tumours of the lung, pleura, thymus and heart. Lyon: 2004; IARC Press.

3. Marino M, and Muller-Hermelink HK. Thymoma and thymic carcinoma. Relation of thymoma epithelial cells to the cortical and medullary differentiation of thymus. Virchows Arch Pathol Anat Histopathol 1985; 407:119-149.

4. Muller-Hermelink HK, and Marx A. Thymoma. Curr Opin Oncol 2000; 12:426-433.

5. Kondo K, and Monden Y. Thymoma and myasthenia gravis: a clinical study of 1,089 patients from Japan. Ann Thorac Surg 2005; 79:219-224.

6. Lewis JE, Wick MR, Scheithauer BW, Bernatz PE, and Taylor WF. Thymoma. A clinicopathologic review. Cancer 1987; 60:2727-2743.

7. Okumura M, Ohta M, Tateyama H, Nakagawa $K$, Matsumura A et al. Masaoka A. The World Health Organization histologic classification system reflects the oncologic behavior of thymoma: a clinical study of 273 patients. Cancer 2002; 94:624-632.

8. Lindstrom JM, Seybold ME, Lennon VA, Whittingham S, and Duane DD. Antibody to acetylcholine receptor in myasthenia gravis: prevalence, clinical correlates, and diagnostic value. Neurology 1998; 51:933-939.

9. Zhang GX, Xiao BG, Bakhiet M, van der Meide P, Wigzell $\mathrm{H}$ et al. Both $\mathrm{CD}^{+}$and $\mathrm{CD} 8^{+} \mathrm{T}$ cells are essential to induce experimental autoimmune myasthenia gravis. J Exp Med
1996; 184:349-356.

10. Vincent A, and Willcox N. The role of T-cells in the initiation of autoantibody responses in thymoma patients. Pathol Res Pract 1999; 195:535-540.

11. Ströbel P, Helmreich M, Menioudakis G, Lewin SR, Rüdiger $\mathrm{T}$ et al. Paraneoplastic myasthenia gravis correlates with generation of mature naive CD4(+) T cells in thymomas. Blood 2002; 100:159-166.

12. Groux H, O'Garra A, Bigler M, Rouleau M, Antonenko S, et al. A CD4 ${ }^{+}$T-cell subset inhibits antigen-specific T-cell responses and prevents colitis. Nature 1997; 389:737-742.

13. Levings MK, Sangregorio R, Galbiati F, Squadrone S, de Waal Malefyt R et al. IFN-alpha and IL-10 induce the differentiation of human type $1 \mathrm{~T}$ regulatory cells. J Immunol 2001; 166:5530-5539.

14. Shevach EM. CD $4^{+} \mathrm{CD} 25^{+}$suppressor T cells: more questions than answers. Nat Rev Immunol 2002; 2:389-400.

15. Luther C, Poeschel S, Varga M, Melms A, and Tolosa E. Decreased frequency of intrathymic regulatory $\mathrm{T}$ cells in patients with myasthenia-associated thymoma. J Neuroimmunol 2005; 164:124-128.

16. Hori S, Nomura T, and Sakaguchi S. Control of regulatory $\mathrm{T}$ cell development by the transcription factor FoxP3. Science 2003; 299:1057-1061.

17. Coutinho A, Caramalho I, Seixas E, and Demengeot J. Thymic commitment of regulatory $\mathrm{T}$ cells is a pathway of TCR-dependent selection that isolates repertoires undergoing positive or negative selection. Curr Top Microbiol Immunol 2005; 293:43-71.

18. Karube K, Aoki R, Sugita Y, Yoshida S, Nomura Y et al. The relationship of FOXP3 expression and clinicopathological characteristics in adult T-cell leukemia/lymphoma. Mod Pathol 2008; 21:617-625.

19. Sakaguchi S, Sakaguchi N, Asano M, Itoh M, and Toda M. Immunologic self-tolerance maintained by activated $\mathrm{T}$ cells expressing IL-2 receptor alpha-chains (CD25). Breakdown of a single mechanism of self-tolerance causes various autoimmune diseases. J Immunol 1995; 155:1151-1164.

20. Fontenot JD, Gavin MA, and Rudensky AY. FoxP3 programs the development and function of $\mathrm{CD} 44^{+} \mathrm{CD} 25^{+}$regulatory T cells. Nat Immunol 2003; 4:330-336.

21. Hori S, and Sakaguchi S. FoxP3: a critical regulator of the development and function of regulatory $\mathrm{T}$ cells. Microbes Infect 2004; 6:745-751.

22. Sakaguchi S. Naturally arising $\mathrm{CD}^{+}{ }^{+}$regulatory $\mathrm{T}$ cells for immunologic self-tolerance and negative control of immune responses. Annu Rev Immunol 2004; 22:531-562.

23. Shevach EM. Regulatory $\mathrm{T}$ cells in autoimmunity. Annu Rev Immunol 2000; 18:423-449.

24. Singh B, Read S, Asseman C, Malmström V, Mottet C et al. Control of intestinal inflammation by regulatory $\mathrm{T}$ cells. Immunol Rev 2001; 182:190-200.

25. Fattorossi A, Battaglia A, Buzzonetti A, Ciaraffa F, Scambia $\mathrm{G}$ et al. Circulating and thymic CD4 CD25 T regulatory cells in myasthenia gravis: effect of immunosuppressive treatment. Immunology 2005; 116:134-141.

26. Wang HB, Zhang JB, and Chui LY. Identification of correlations between numbers of $\mathrm{CD} 4{ }^{+} \mathrm{CD} 25^{+}$Tregs cells, levels of sera anti-AchR antibodies and transfer growth factorbeta in patients with myasthenia gravis [Article in Chinese]. 
Zhonghua Yi Xue Za Zhi 2008; 88:1036-1040.

27. Heldal AT, Eide GE, Romi F, Owe JF, and Gilhus NE. Repeated acetylcholine receptor antibody-concentrations and association to clinical myasthenia gravis development. PLos One 2014 Dec 2; 9:e114060.

28. Morikawa H, Ohkura N, Vandenbon A, Itoh M, Nagao-Sato
$\mathrm{S}$ et al. Differential roles of epigenetic changes and FoxP3 expression in regulatory $\mathrm{T}$ cell-specific transcriptional regulation. Proc Natl Acad Sci U S A 2014; 111:5289-5294.

29. Zhang Y, Wang HB, Chi LJ, and Wang WZ. The role of FoxP $3^{+} \mathrm{CD}^{+} 6 \mathrm{CD} 25^{\text {hi }}$ Tregs in the pathogenesis of myasthenia gravis. Immunol Lett 2009; 122:52-57. 